\title{
The Effect of FDA Drug Safety Communications on Patterns of Tiotropium Dispensing: A U.S. Health Plan Claims Database Study
}

\author{
Jacqueline M. Major, PhD; Esther H. Zhou, MD, PhD; Yulan Ding, MPH; Thomas Ly, PhD; \\ Jie Li, PhD; Simone P. Pinheiro, ScD, MSc; and Sally Seymour, MD
}

\begin{abstract}
BACKGROUND: The FDA issued 2 main drug safety communications (DSCs) on the cardiovascular safety of tiotropium in March 2008 (warning of a potential increased stroke risk) and January 2010 (informing of an absence of a significant increased stroke risk or cardiovascular events based on findings from a large trial).
\end{abstract}

OBJECTIVE: To describe the effect of the FDA DSCs on medication dispensing of tiotropium in a large U.S. claims database.

METHODS: Initiation of tiotropium products among patients with chronic obstructive pulmonary disease (COPD) aged 40 years and older was determined monthly from 2006-2012 using medication dispensing from the IMS Lifelink Health Plan Claims Database. Similarly, monthly initiation of products containing long-acting beta-agonists (LABAs) was calculated to explore product switching. The effect of the 2008 and 2010 FDA DSCs was measured using interrupted time-series analysis. Subgroups of patients with greater cardiovascular risk were also examined.

RESULTS: A decreasing trend in initiation of tiotropium-containing products was present before the initial 2008 DSC. The decline in tiotropium initiation continued until January 2010, accompanied by an increased initiation of LABA-containing products in patients with COPD. In the presence of the existing decreasing trend, the initial DSC was followed by an immediate $2.8 \%(P=0.02)$ further reduction in tiotropium initiation. Tiotropium initiation increased $2.5 \%(P=0.03)$ immediately after the $2010 \mathrm{DSC}$, reducing the overall decline in rate and stabilizing (flattening) the trend. No significant changes in dispensing level or trend were observed among COPD patients with cardiovascular comorbidity.

CONCLUSIONS: Cardiovascular safety concerns may have affected tiotropium initiation as indicated by the decrease in tiotropium dispensing shown immediately following the initial DSC. The effect was alleviated as concerns lessened following the most recent DSC.

J Manag Care Spec Pharm. 2018;24(7):700-09

Copyright $\odot 2018$, Academy of Managed Care Pharmacy. All rights reserved.

\section{What is already known about this subject}

The FDA issued 2 main drug safety communications (DSCs) on the cardiovascular safety of tiotropium in March 2008 and January 2010.

- The 2010 DSC informed of an absence of increased risk for stroke and cardiovascular events based on findings from a large trial.

\section{What this study adds}

This study offers a careful review of the effect of 2 safety communications on patterns of tiotropium dispensing.

Safety concerns regarding the cardiovascular effects of tiotropium were associated with a $3 \%$ decrease in the prescriptions dispensed in the United States following the 2008 DSC, but the decline decreased and the trend stabilized following the 2010 DSC.

These findings have implications for patients and clinicians who rely on the FDA to communicate drug safety information to inform their medication-related health care decisions.

$\mathrm{T}$ iotropium bromide is a long-acting anticholinergic that was approved in the United States in January 2004 for treatment of chronic obstructive pulmonary disease (COPD), a leading cause of death worldwide., ${ }^{1,2}$ The U.S. Food and Drug Administration (FDA) continuously evaluates the safety of approved drugs and uses drug safety communications (DSCs) to inform the public about ongoing or completed reviews of potential serious safety signals. In March 2008, the FDA issued a DSC describing an ongoing review based on pooled data submitted by the manufacturer that suggested there may be a small excess risk of stroke ( 2 cases per 1,000 treated patients) with tiotropium over placebo. ${ }^{3}$ In October 2008, the FDA updated the DSC to note 2 additional publications that suggested an increased risk of myocardial infarction, stroke, or death in patients using tiotropium or drugs that work similarly to tiotropium. ${ }^{4,5}$

To evaluate the safety issue, the FDA analyzed data from the Understanding the Potential Long-Term Impacts on Function with Tiotropium (UPLIFT) trial. ${ }^{6}$ UPLIFT was a large, 4-year clinical trial that compared tiotropium with placebo in 5,992 COPD patients. In the UPLIFT trial, there was no significant increase in the risk of myocardial infarction (relative risk $[\mathrm{RR}]=0.73,95 \%$ confidence interval $[\mathrm{CI}]=0.53-1.00)$; stroke $(\mathrm{RR}=0.95,95 \% \mathrm{CI}$ : 0.70-1.29); or cardiovascular death (hazard ratio $=0.73,95 \%$ $\mathrm{CI}=0.56-0.96)$ between tiotropium and placebo.

In November 2009, the FDA Pulmonary-Allergy Drugs Advisory Committee reviewed data from the UPLIFT trial and voted that the UPLIFT findings adequately addressed the potential safety concerns for stroke, myocardial infarction, and cardiovascular death with tiotropium. ${ }^{7}$ Given the strength 
TABLE 1 Characteristics of Incident Users of Tiotropium and LABA-Containing Products by Study Period

\begin{tabular}{|c|c|c|c|c|c|c|c|c|}
\hline & \multicolumn{4}{|c|}{ Tiotropium } & \multicolumn{4}{|c|}{ LABA } \\
\hline & $\begin{array}{c}2006-2012 \\
(\mathrm{~N}=54,004)\end{array}$ & $\begin{array}{l}\text { Period } 1^{\mathrm{a}} \\
(\mathrm{n}=15,029)\end{array}$ & $\begin{array}{c}\text { Period 2b } \\
(\mathrm{n}=17,388)\end{array}$ & $\begin{array}{c}\text { Period } 3^{c} \\
(n=21,587)\end{array}$ & $\begin{array}{c}2006-2012 \\
(\mathrm{~N}=58,502)\end{array}$ & $\begin{array}{c}\text { Period } 1^{\mathrm{a}} \\
(\mathrm{n}=13,646)\end{array}$ & $\begin{array}{l}\text { Period } 2^{\mathrm{b}} \\
(\mathrm{n}=19,969)\end{array}$ & $\begin{array}{c}\text { Period } 3^{c} \\
(\mathrm{n}=24,887)\end{array}$ \\
\hline \multicolumn{9}{|l|}{ Age at index, years } \\
\hline Mean (SD) & $67(11)$ & $67(11)$ & $67(12)$ & $67(12)$ & $67(12)$ & $67(12)$ & $67(12)$ & $66(12)$ \\
\hline \multicolumn{9}{|l|}{ Age group at index } \\
\hline $40-64$ & 47 & 47 & 45 & 48 & 48 & 47 & 46 & 49 \\
\hline $65+$ & 53 & 53 & 55 & 52 & 52 & 53 & 54 & 51 \\
\hline Female & 47 & 46 & 47 & 47 & 48 & 47 & 47 & 48 \\
\hline Cardiovascular comorbidities & 29 & 29 & 30 & 28 & 28 & 29 & 28 & 27 \\
\hline Prior LABA & 31 & 30 & 30 & 32 & & & & \\
\hline Prior tiotropium & & & & & 25 & 23 & 26 & 26 \\
\hline \multicolumn{9}{|l|}{ Days supply at index } \\
\hline 30 days & 86 & 86 & 86 & 87 & 86 & 86 & 85 & 87 \\
\hline 31-89 days & 1 & 1 & 0 & 0 & 2 & 2 & 2 & 2 \\
\hline 90 days & 13 & 12 & 14 & 12 & 12 & 12 & 13 & 11 \\
\hline \multicolumn{9}{|c|}{$\begin{array}{l}\text { Note: All values shown in table are percentages, unless otherwise indicated. } \\
\text { aPeriod } 1=\text { January 2006-February } 2008 . \\
\text { beriod } 2=\text { March 2008-December } 2009 . \\
\text { cPeriod } 3=\text { January 2010-December } 2012 . \\
\text { dDuring } 12 \text { months before initiation of drug product. } \\
\text { LABA=long-acting beta-agonist; SD = standard deviation. }\end{array}$} \\
\hline
\end{tabular}

of the UPLIFT trial and absence of a strong signal related to cardiovascular events, the FDA issued the last DSC in January 2010 , stating that the available data did not support an association between use of tiotropium and an increased risk for stroke, heart attack, or cardiovascular death. ${ }^{8,9}$ The effect of the FDA DSCs on tiotropium use, as well as the effect of the different types of communications, is unknown.

The purpose of this study was to examine the effect of the initial 2008 DSC (announcing a potential safety signal) and the 2010 DSC (concluding that the available data from the UPLIFT trial did not support the safety signal) on dispensing patterns of tiotropium among medicated patients with COPD. This examination fills an important gap in understanding the effects of FDA communications and to help future communication efforts.

\section{Methods}

\section{Data Source}

The IMS Lifelink Health Plan Claims Database is a proprietary data source that comprises adjudicated medical and pharmaceutical claims from approximately 100 managed care plans across the United States. ${ }^{10}$ The database contains longitudinal data of medical claims for over 68 million de-identified patients, including inpatient and outpatient diagnoses (International Classification of Diseases, Ninth Revision, Clinical Modification [ICD-9-CM] format) and procedures (Current Procedural Terminology $[\mathrm{CPT}]$ and Healthcare Common Procedure Coding System [HCPCS] formats), in addition to retail and mail order prescription records (e.g., National Drug Code number and quantity dispensed). This study was exempted from review by the FDA Research Involving Human Subjects Committee under 45 CFR 46 101(b)(4). All patient information was de-identified by the claims database vendor before providing the information used to build the analytic dataset for this study.

\section{Study Period}

The study period spanned from January 2006 through December 2012, with the initial DSC regarding tiotropium safety concerns issued in March 2008 and the last DSC issued in January 2010 to notify the public that the data reviewed did not support an increase in risk. We defined 3 time segments: a baseline period (period 1: January 2006-February 2008); a post-2008 DSC period (period 2: March 2008-December 2009); and a post-2010 DSC period (period 3: January 2010-December 2012).

\section{Study Population}

Incident users (initiators) of tiotropium were COPD patients with the first prescription of tiotropium dispensed between January 1, 2006, and December 31, 2012 (i.e., without prescriptions of tiotropium in the previous 12 months). Patients who also met the following selection criteria were included in the study cohort: (a) index tiotropium prescription dispensed with a 30- to 90-day supply, with the index date defined as the date of the first tiotropium prescription; (b) aged 40 years 


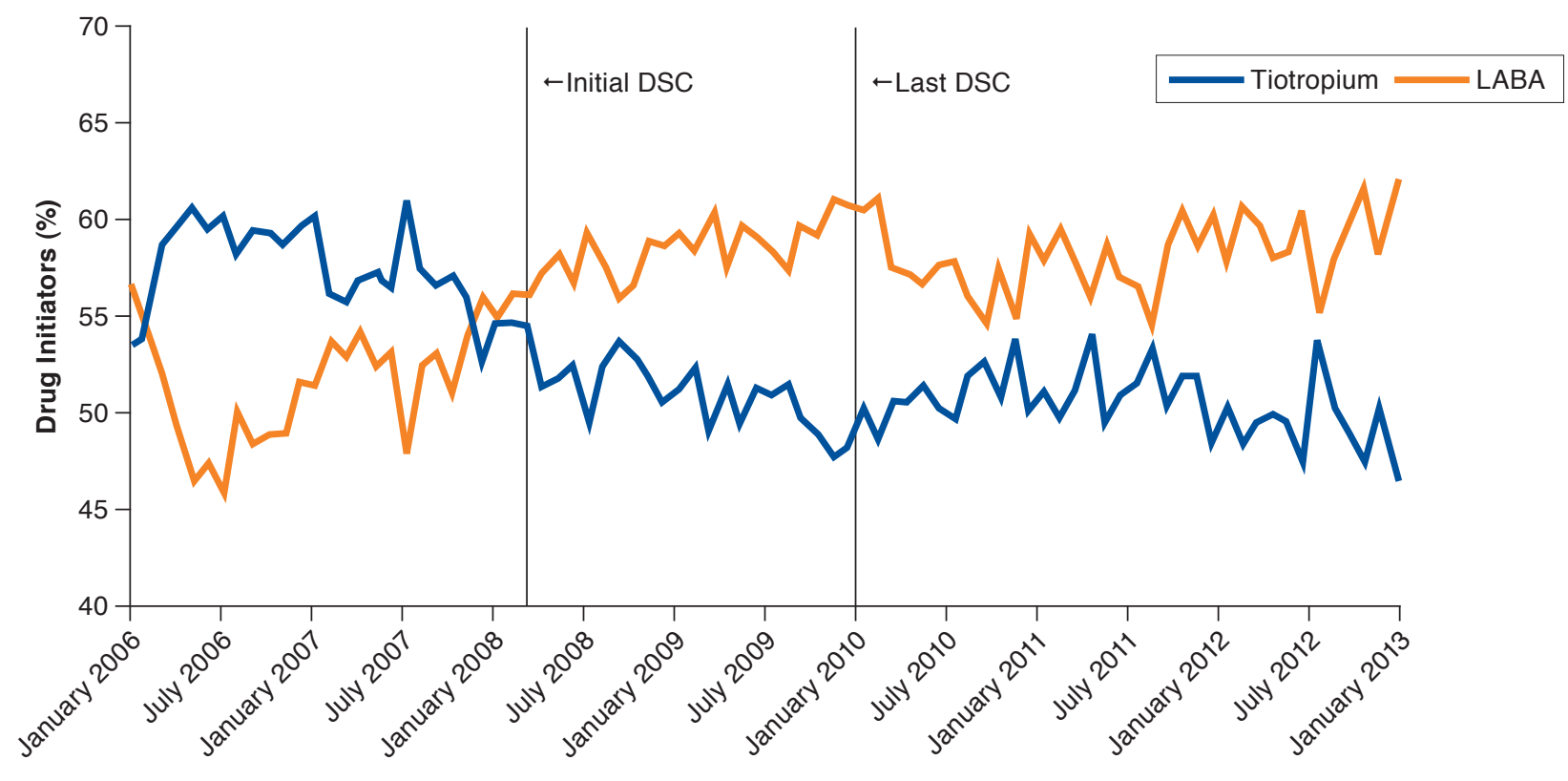

Note: Initial DSC was issued in March 2008; last DSC was issued in January 2010.

$C O P D=$ chronic obstructive pulmonary disease; $D S C=$ drug safety communication; LABA=long-acting beta-agonist.

or older at index date; (c) continuously enrolled in a health plan during the 12 months before the index date; and (d) at least 2 COPD diagnoses on or within 12 months preceding the index date (e.g., chronic bronchitis, emphysema, or chronic airway obstruction-ICD-9-CM codes 491, 492, and 496, respectively). We excluded patients with an asthma diagnosis (ICD-9-CM code 493) on the index date or within the 12 months preceding the index date, since there may be an offlabel use of tiotropium for asthma. ${ }^{11}$ Tiotropium bromide was the only long-acting anticholinergic drug approved by the FDA until late 2012. Therefore, a comparison group of long-acting beta-agonist (LABA) initiators was established using similar criteria to those just described, given that LABA is an alternative long-acting bronchodilator for maintenance treatment of COPD. ${ }^{2,12}$ Patients in the tiotropium group with a LABA dispensing before tiotropium initiation were not excluded from the tiotropium new user group. Patients who initiated tiotropium and LABA in the same month contributed to both groups; however, patients could enter the study only once and could not reinitiate the same product during the study period.

\section{Statistical Analysis}

We graphically examined the monthly initiation of tiotropium and LABA-containing products among COPD patients across the study period (2006-2012). To measure the effect of the 2 DSCs, we used an interrupted time-series (ITS) analysis with segmented linear regression to estimate changes in level and trend of tiotropium initiation between periods 1 and 2 (pre-post initial DSC) and between periods 2 and 3 (pre-post last DSC), ${ }^{13-16}$ while accounting for the baseline trend. As a comparator with tiotropium initiators, we also examined LABA initiation to explore potential channeling of COPD patients from tiotropium to LABA-containing products. For each month, the proportion of treatment-specific new users was calculated as the number of COPD patients who were dispensed a new prescription (e.g., tiotropium) divided by the total number of COPD patients newly initiating a medication.

As a sensitivity analysis, we excluded patients who initiated tiotropium and LABA during the same month. In secondary analyses, patients were stratified by age group (40-64 and 65+ years) and presence of the following cardiovascular comorbidities: stroke (ICD-9-CM codes 430, 431, 432, 433.01 433.11, 433.21, 433.31, 433.81, 433.91, 434.01, 434.11, 434.91, and 436); myocardial infarction (ICD-9-CM codes 410, 411, and 412); ischemic heart disease (ICD-9-CM codes 410, 411, 412, 413, and 414); and cardiac arrhythmia (ICD-9-CM code 427) to explore potential differences in higher-risk COPD patients. ${ }^{17,18}$ Because the effect of a DSC may not be apparent immediately after being issued, an additional sensitivity analysis incorporated a latency period of 3 months after each DSC. 
TABLE 2 Summary of ITS Analysis Among New Users of Tiotropium and LABA

\begin{tabular}{l}
\hline \\
\cline { 2 - 9 }
\end{tabular}

The ITS analysis accounted for the overall trend in rates and autocorrelation using the AR(1) model, ${ }^{15}$ and the DurbinWatson test suggested the existence of autocorrelations. Other diagnostic tests included the assessment of normality of the residuals, heteroscedasticity, and the Dicky-Fuller statistic for stationarity, which suggested a normal residual distribution and lack of heteroscedasticity and seasonality. All calculated $P$ values were two-sided, and all statistical analyses were conducted using SAS statistical software version 9.4 (SAS Institute, Cary, NC).

\section{Results}

We identified 54,004 tiotropium initiators aged 40 years or older with at least 1 new tiotropium prescription dispensed who met the inclusion criteria during the study period (January 2006 through December 2012), with the average number of monthly new users of 643 (standard deviation [SD] 138). Eighty-six percent of the tiotropium prescriptions were for a 30-day supply, and the median number of prescriptions per patient during the study period was 4 (25th to 75 th percentiles: 2 to 10). Table 1 shows patient characteristics among the 2 treatment groups before and after the DSCs. Of the 15,029 patients aged 40 years or older who initiated tiotropium during the baseline period, 53\% were aged 65 years and older. Twentynine percent of the patients had previous cardiovascularrelated comorbidities. For the comparison group, we identified 58,502 LABA initiators, with the average number of monthly users of 697 (SD 189). No significant changes in demographics were observed after the March 2008 or January 2010 communications. The demographics for the LABA initiators were similar to those of the tiotropium initiators.

\section{Trends over Time}

The patterns of monthly product-specific initiation among COPD patients across the 84-month study period are shown in Figure 1. Before the release of the initial DSC in March 2008, the average monthly tiotropium initiation was $58 \%$ of those with COPD who initiated either tiotropium or LABA (data not shown), with an overall decreasing trend from January 2006 to February 2008 (period 1). After the initial communication, the tiotropium initiation was lower (average of 51\%) from March 2008 through December 2009 and appeared to continue to decline over the subsequent 22 months (period 2). The trend appeared to level off following the last DSC in January 2010; the average monthly initiation of tiotropium in period 3 was approximately $51 \%$ of COPD patients who initiated either treatment. In turn, the pattern of LABA initiation showed an increasing trend before and after the early communication and a suggested stabilization (flattening) after the follow-up communication in January 2010.

Results of the ITS analysis are reported in Table 2, including the statistical significance of changes in initiation level and trend. As shown, the initial DSC was associated with an immediate 2.8\% $(P=0.02)$ absolute reduction after accounting for the baseline level in COPD patients initiating tiotropium, which corresponded to an increase of similar magnitude for LABA initiators (2.6\% increase, $P=0.11)$. Immediately after the 2010 DSC, however, the dispensing rate increased 2.5\% $(P=0.03)$ for tiotropium initiators, reducing the overall decline in rate and stabilizing (flattening) the trend. The segmented regression lines for tiotropium are shown in Figure 2. Among LABA initiators, a reduction of $2.6 \%(P=0.09)$ in the monthly dispensing rate was observed after the 2010 DSC. Before the communications, the baseline trend in prescription dispensing pattern for tiotropium suggested a downward slope (slope $=-0.11$, $P=0.059$ ); however, after the initial communication, the downward slope became less steep (slope $=-0.09$ ) and was no longer statistically significant $(P=0.33)$. After the last DSC, there was no longer a downward slope (slope $=0.13, P=0.09$ ). Segmented regression lines for LABA are provided in Appendix A (available in online article).

Age-stratified analyses showed a significant decrease in the dispensing rate of COPD patients initiating tiotropium (4.6\% absolute decrease, $P=0.01$ ) among patients aged 40-64 years following the initial DSC (Appendix B, available in 


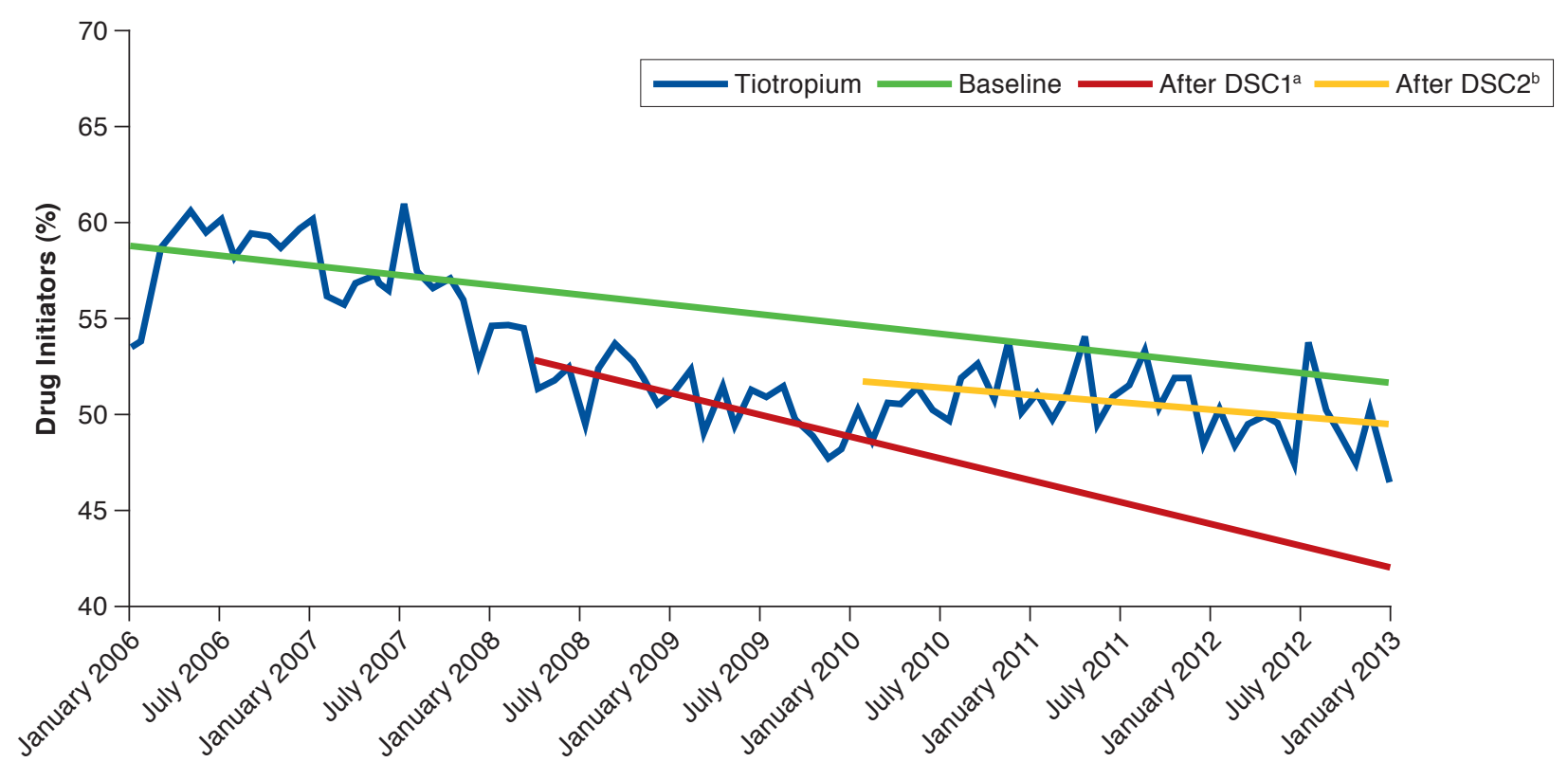

Note: Estimated trend lines are based on segmented regression model.

aAfter March 2008.

bAfter January 2010.

$\mathrm{COPD}=$ chronic obstructive pulmonary disease; $\mathrm{DSC}=$ drug safety communication.

online article, and Figure 3). Among patients aged 65 years and older, there was no evidence of an immediate effect as a result of the initial DSC; however, an increase in the level change in rate following the last DSC in January 2010 was statistically significant $(3.5 \%$ absolute increase, $P<0.001)$. For the LABA initiators, no significant changes in dispensing rates (i.e., level or trend) were observed among patients aged 40-64 years. However, the absolute level change in dispensing rate decreased 3\% $(P=0.04)$ among patients aged 65 years and older. For tiotropium and LABA initiators, no significant changes were observed among patients with cardiovascular comorbidity (Appendix B). Sensitivity analyses with 3-month lag did not differ substantively from the results of the primary analysis (Appendix B).

\section{Discussion}

This study examined the effect of 2 main FDA DSCs that addressed cardiovascular safety concerns of tiotropium on product initiation over a 7 -year period using a large, adjudicated U.S. health plan claims database. A decreasing trend in tiotropium initiation was present before the initial DSC in 2008. ITS analyses suggest the initial DSC was followed by an immediate 2.8\% $(P=0.02)$ absolute reduction in tiotropium initiation, after accounting for the baseline trend observed before the initial
DSC, and a continuous decreasing trend (-0.09\% per month) until the 2010 DSC. The initiation of tiotropium increased immediately after the 2010 DSC, reducing the overall decline in rate and stabilizing the trend. It is possible that regulatory actions on safe use of LABAs in asthma patients may have had an unintended effect on use among COPD patients following the DSC for LABAs in early 2010, which may explain, in part, the decrease in LABA initiation and slight uptake in tiotropium that then remained relatively stable between 2010 and 2012.

In addition, the decrease of tiotropium dispensing after the initial DSC coincided with the timing of other events, such as the publications reporting drug safety risks and the October 2008 update to the initial DSC. ${ }^{3-5}$ These events may have increased the awareness of potential safety concerns among health care providers and patients and possibly contributed to the continued decline in dispensing rates for tiotropium initiators. ${ }^{19}$ Although we might have expected the observed decrease to be greater than a $2.8 \%$ reduction, the 2008 published findings from the UPLIFT trial, ${ }^{6}$ finding no significant risks, may have alleviated some concerns in the health care provider community, thereby reducing the full potential effect of the initial DSC.

We hypothesized that the safety warnings for tiotropium would have a greater effect on COPD patients at higher risk 


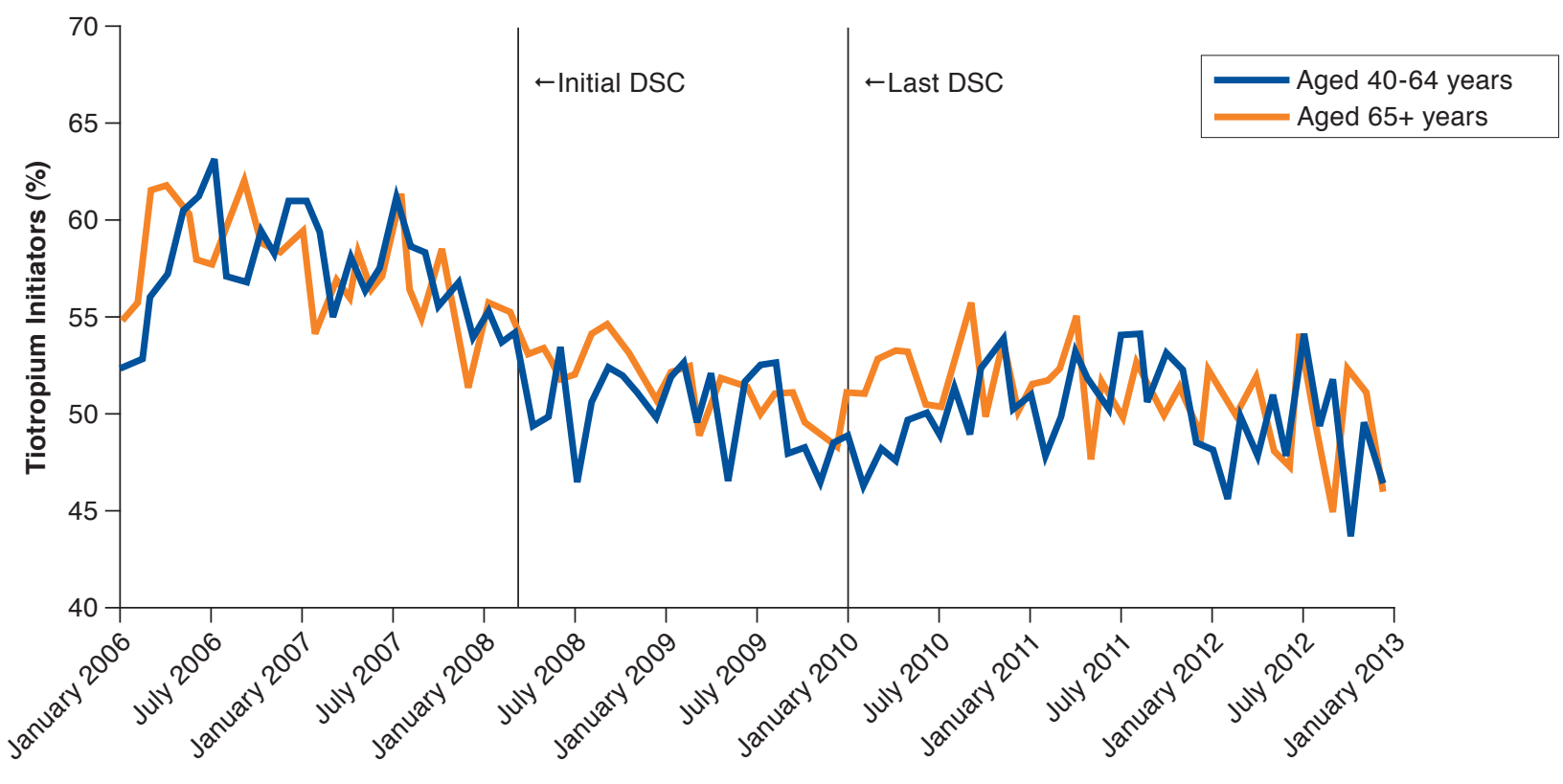

Note: Initial DSC was issued in March 2008; last DSC was issued in January 2010. $C O P D=$ chronic obstructive pulmonary disease; $D S C=$ drug safety communication .

of cardiovascular-related adverse outcomes (i.e., patients aged 65 years and older and those with cardiovascular comorbidities). Findings from this study, however, showed a statistically significant decrease in tiotropium dispensing after the initial DSC among younger COPD patients, not older patients. An increase in tiotropium dispensing among older COPD patients was observed after the 2010 DSC. This study does not account for patient-level information, such as severity of COPD or other clinically relevant factors possibly used in making prescribing decisions, which may partly explain the difference observed between the 2 age groups. Stratified results should be interpreted with caution given the increased variation due to the smaller sample sizes in the subgroups and underrepresentation of the elderly in the claims database. No significant changes in dispensing level or trend were observed among COPD patients with cardiovascular comorbidity.

Similar to this study, a number of studies have examined changes in dispensed prescriptions following regulatory actions (e.g., public health advisory, boxed warning, and labeling change) informing of a potential increase in risk. ${ }^{20,21}$ While the magnitude of the effects of these actions varied across drugs and types of events, many studies reported an expected decline of dispensed prescriptions after the event. The heterogeneity of drugs and type of communications examined did not allow the estimation of an "average" magnitude of effect. In a recent study among adult asthma patients initiating LABA treatment, a $1 \%$ decrease in LABA dispensings was observed following a 2005 DSC. ${ }^{22}$ The FDA communications examined in this study are unique in that the initial DSC was an early communication about an ongoing review of a safety signal and warned of a potential increased risk, whereas the 2010 DSC was a conclusion of the FDA review, noting that the available data did not support the safety signal. Therefore, this study provides new insight on the potential effect that different types of messages have on drug utilization (dispensing) patterns.

\section{Limitations}

While a strength of this study is the inclusion of a relatively large number of patients, there are some limitations that need to be considered. Findings from this study are based on aggregate data, which preclude us from directly examining product discontinuation or switching (e.g., tiotropium to LABA products or other products) by patients or accounting for patient-specific clinical information (e.g., severity of a patient's COPD) that might have influenced drug prescribing patterns. Although this study did not evaluate utilization and/or switching to other medications (including ipratropium), switching from tiotropium to ipratropium may be limited given differences in length of action and dosage regimens.

Since multiple events took place during the study period, this study cannot isolate the effect of the tiotropium DSCs nor evaluate the role of the media, insurance coverage, and 
out-of-pocket cost in the observed trends. Potential influences of product "aging" or approval of other agents were not assessed but may have contributed in part to the apparent secular decrease in tiotropium before the initial DSC. The IMS LifeLink database does not include Medicare coverage, so the elderly population is likely underrepresented in this study. Similarly, results are not generalizable to the uninsured or publicly insured populations.

DSCs remain a key tool used by the FDA to communicate postapproval drug safety issues, so understanding their effects is therefore important. The FDA continues to have a significant challenge navigating between the need for transparency and efficiency in releasing emerging safety data that are not yet mature (and may ultimately not be borne out) with possible unintended consequences and the withholding of emerging safety data that might jeopardize patient safety. ${ }^{23}$ As such, this study is an important examination of this issue.

While demonstrating that the DSC was temporally related to changes in prescription dispensing patterns for tiotropium with 2 DSCs, we also found the counterintuitive lack of relationship between the DSC and those patients who might be at most risk (based on the DSC). As such, there is more research needed. This study, however, provides a template for others to follow in addressing this important issue.

\section{Conclusions}

This study's finding that initial safety concerns regarding the cardiovascular effects of tiotropium were associated with a decrease in the initiation of this drug in the United States and that the last safety communication associated with a reversal of this decline suggests that the FDA's 2008 and 2010 DSCs may have affected the initiation of tiotropium medication dispensing among COPD patients. Future studies are needed to evaluate patient-level, nonaggregated use of COPD medications to adequately examine individual treatment patterns, including discontinuation of tiotropium, in older study populations.

\section{Authors}

JACQUELINE M. MAJOR, PhD; ESTHER H. ZHOU, MD, PhD; YULAN DING, MPH; JIE LI, PhD; and SIMONE P. PINHEIRO, ScD, MSc, Office of Surveillance and Epidemiology, Center for Drug Evaluation and Research, U.S. Food and Drug Administration, Silver Spring, Maryland. THOMAS LY, PhD, Office of Biostatistics, and SALLY SEYMOUR, MD, Office of New Drugs, Center for Drug Evaluation and Research, U.S. Food and Drug Administration, Silver Spring, Maryland.

AUTHOR CORRESPONDENCE: Jacqueline M. Major, PhD, Office of Surveillance and Epidemiology, Center for Drug Evaluation and Research, U.S. Food and Drug Administration, 10903 New Hampshire Ave., Silver Spring, MD 20993.

Tel.: 240.402.0342; E-mail: Jacqueline.Major@fda.hhs.gov.

\section{DISCLOSURES}

This research did not receive any specific grant from funding agencies in the public, commercial, or not-for-profit sectors. The authors are employed by the FDA and have no conflict of interest relevant to the content of this study. The views expressed herein do not necessarily represent the views of the FDA.

\section{ACKNOWLEDGMENTS}

The authors acknowledge the contributions of Solomon Iyasu, MD; Elizabeth Kang, MPH; Tracy Pham, PharmD; and Hina Mehta, PharmD, for their advice and commentary on the study protocol and analysis plan. The authors also thank Kang for programming assistance. Iyasu and Kang departed the FDA before finalization of the manuscript.

\section{REFERENCES}

1. World Health Organization. The top 10 causes of death. Fact sheet. January 12, 2017. Available at: http://www.who.int/mediacentre/factsheets/ fs310/en/. Accessed May 9, 2018

2. Global Initiative for Chronic Obstructive Lung Disease. Global strategy for diagnosis, management, and prevention of COPD 2016. Available at: http://goldcopd.org/global-strategy-diagnosis-management-preventioncopd-2016/. Accessed May 9, 2018.

3. U.S. Food and Drug Administration. Early communication about an ongoing safety review of tiotropium (marketed as Spiriva HandiHaler). October 7, 2008. Available at: https://wayback.archive-it.org/7993/2017 0406045706/https://www.fda.gov/Drugs/DrugSafety/PostmarketDrug SafetyInformationforPatientsandProviders/DrugSafetyInformationfor HeathcareProfessionals/ucm070651.htm. Accessed May 9, 2018.

4. Singh S, Loke YK, Furberg CD. Inhaled anticholinergics and risk of major adverse cardiovascular events in patients with chronic obstructive pulmonary disease: a systematic review and meta-analysis. JAMA. 2008;300(12):1439-50.

5. Lee TA, Pickard AS, Au DH, Bartle B, Weiss KB. Risk for death associated with medications for recently diagnosed chronic obstructive pulmonary disease. Ann Intern Med. 2008;149(6):380-90

6. Tashkin DP, Celli B, Senn S, et al. A 4-year trial of tiotropium in chronic obstructive pulmonary disease. N Engl J Med. 2008;359(15):1543-54. Available at: https://www.nejm.org/doi/10.1056/NEJMoa0805800?url_ ver=Z39.88-2003\&rfr_id=ori:rid:crossref.org $\&$ rfr_dat=cr_pub\%3dwww. ncbi.nlm.nih.gov. Accessed May 9, 2018.

7. U.S. Food and Drug Administration. Summary minutes of the Pulmonary-Allergy Drugs Advisory Committee (PADAC). UCM196995. November 19, 2009. Available at: https://wayback.archive-it.org/7993/ 20170404155911/https://www.fda.gov/downloads/AdvisoryCommittees/ CommitteesMeetingMaterials/Drugs/Pulmonary-AllergyDrugsAdvisory Committee/UCM196995.pdf. Accessed May 9, 2018

8. U.S. Food and Drug Administration. Follow-up to the October 2008 updated early communication about an ongoing safety review of tiotropium (marketed as Spiriva HandiHaler). January 14, 2010. Available at: https:// wayback.archive-it.org/7993/20170722191618/https://www.fda.gov/Drugs/ DrugSafety/PostmarketDrugSafetyInformationforPatientsandProviders/ DrugSafetyInformationforHeathcareProfessionals/ucm197429.htm. Accessed May 9, 2018.

9. Michele TM, Pinheiro S, Iyasu S. The safety of tiotropium-the FDA's conclusions. N Engl J Med. 2010;363(12):1097-99. Available at: https:// www.nejm.org/doi/10.1056/NEJMpl008502?url_ver=Z39.88-2003\&rfr_ id=ori:rid:crossref.org\&rfr_dat=cr_pub\%3dwww.ncbi.nlm.nih.gov. Accessed May 9, 2018 
10. IMS Consulting Group. Information exchange presentation \& discussion. LifeLink Health Plan Claims Database. October 6, 2011. Available at: https://www.jhsph.edu/offices-and-services/career-services/for-students/ career-resources/Public\%20Health\%20Employers/2011-12_Employer_ Information_Sessions/IMS_Consulting_Group_Presentation_Sildes_ Oct_6_2011.pdf. Accessed May 25, 2018.

11. Peters SP, Kunselman SJ, Icitovic N, et al. Tiotropium bromide step-up therapy for adults with uncontrolled asthma. N Engl J Med. 2010;363(18):1715-26. Available at: https://www.nejm.org/doi/10.1056/ NEJMoal008770?url_ver=Z39.88-2003\&rfr_id=ori:rid:crossref.org\&rfr_ dat=cr_pub\%3dwww.ncbi.nlm.nih.gov. Accessed May 9, 2018.

12. Diette GB, Dalal AA, D'Souza AO, Lunacsek OE, Nagar SP. Treatment patterns of chronic obstructive pulmonary disease in employed adults in the United States. Int J Chron Obstruct Pulmon Dis. 2015;10:415-22. Available at: https://www.ncbi.nlm.nih.gov/pmc/articles/PMC4346014/. Accessed May 9, 2018.

13. Box GEP, Jenkins GM, Reinsel GC, Ljung GM. Time Series Analysis: Forecasting and Control. Hoboken, NJ: John Wiley; 2016.

14. Penfold RB, Zhang F. Use of interrupted time series analysis in evaluating health care quality improvements. Acad Pediatr. 2013;13 (6 Suppl):S38-S44.

15. Wagner AK, Soumerai SB, Zhang F, Ross-Degnan D. Segmented regression analysis of interrupted time series studies in medication use research. J Clin Pharm Ther. 2002;27(4):299-309.

16. Zhang F, Wagner AK, Soumerai SB, Ross-Degnan D. Methods for estimating confidence intervals in interrupted time series analyses of health interventions. J Clin Epidemiol. 2009;62(2):143-48.
17. Wise RA, Anzueto A, Cotton D, et al. Tiotropium respimat inhaler and the risk of death in COPD. N Engl J Med. 2013;369(16):1491-501. Available at: https://www.nejm.org/doi/10.1056/NEJMoal303342?url_ver=Z39.882003\&rfr_id=ori:rid:crossref.org\&rfr_dat=cr_pub\%3dwww.ncbi.nlm.nih. gov. Accessed May 9, 2018.

18. Halbert RJ, Natoli JL, Gano A, Badamgarav E, Buist AS, Mannino DM. Global burden of COPD: systematic review and meta-analysis. Eur Respir J. 2006;28(3):523-32. Available at: http://erj.ersjournals.com/content/28/3/523. long. Accessed May 9, 2018.

19. Karpel JP, Peters JI, Szema AM, Smith B, Anderson PJ. Differences in physicians' self-reported knowledge of, attitudes toward, and responses to the black box warning on long-acting beta-agonists. Ann Allergy Asthma Immunol. 2009;103(4):304-10.

20. Briesacher BA, Soumerai SB, Zhang F, et al. A critical review of methods to evaluate the impact of FDA regulatory actions. Pharmacoepidemiol Drug Saf. 2013;22(9):986-94. Available at: https://www.ncbi.nlm.nih.gov/pmc/ articles/PMC3825208/. Accessed May 9, 2018.

21. Dusetzina SB, Higashi AS, Dorsey ER, et al. Impact of FDA drug risk communications on health care utilization and health behaviors-a systematic review. Med Care. 2012;50(6):466-78.

22. Zhou EH, Seymour S, Goulding MR, Kang EM, Major JM, Iyasu S. The US Food and Drug Administration's drug safety recommendations and longacting beta2-agonist dispensing pattern changes in adult asthma patients: 2003-2012. J Asthma Allergy. 2017;10:67-74.

23. Dal Pan GJ, Temple R. Balancing transparency and uncertainty. Arch Intern Med. 20129;172(1):74-75. 


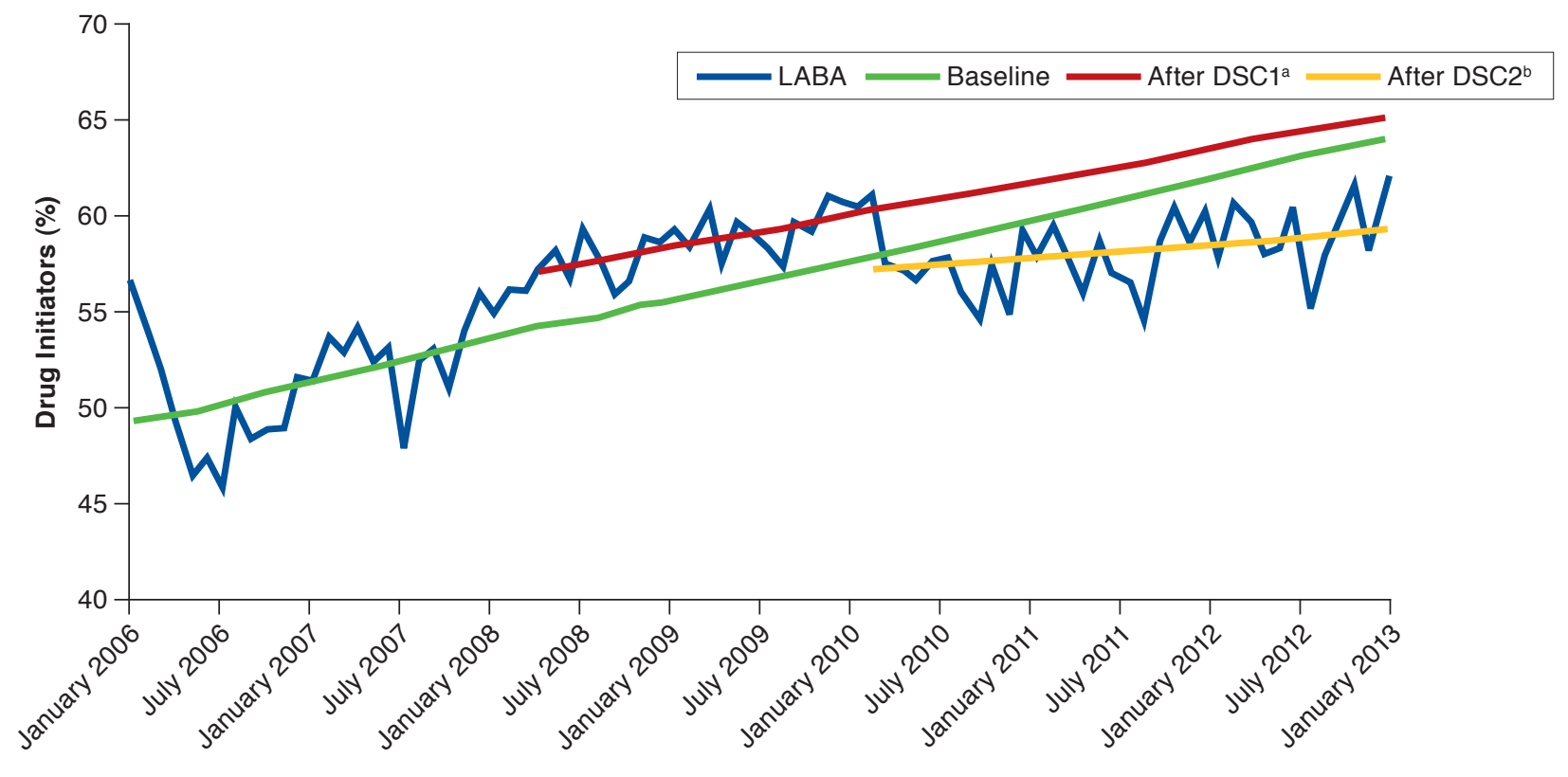

Note: Estimated trend lines are based on segmented regression model.

aAfter March 2008.

bAfter January 2010.

COPD = chronic obstructive pulmonary disease; DSC = drug safety communication; LABA=long-acting beta-agonist. 


\section{APPENDIX B Summary of Stratified ITS Analysis of Tiotropium Initiators By Age Group and Cardiovascular} Comorbidity Status

\begin{tabular}{|c|c|c|c|c|c|c|}
\hline \\
\hline \multicolumn{7}{|l|}{ Aged $40-64$ years } \\
\hline Baseline level & 58.070 & 1.28 & $<0.001$ & 49.800 & 1.62 & $<0.001$ \\
\hline Level change after initial DSC & -4.590 & 1.80 & 0.013 & 3.300 & 2.13 & 0.125 \\
\hline Level change after last DSC & 1.190 & 1.64 & 0.473 & -2.470 & 1.99 & 0.218 \\
\hline Baseline trend & -0.050 & 0.08 & 0.561 & 0.160 & 0.10 & 0.117 \\
\hline Trend change after initial DSC & -0.100 & 0.13 & 0.467 & 0.002 & 0.17 & 0.989 \\
\hline Trend change after last DSC & 0.130 & 0.12 & 0.265 & -0.120 & 0.15 & 0.426 \\
\hline \multicolumn{7}{|l|}{ Aged $65+$ years } \\
\hline Baseline level & 59.900 & 0.76 & $<0.001$ & 49.240 & 1.05 & $<0.001$ \\
\hline Level change after initial DSC & -1.100 & 1.10 & 0.322 & 1.950 & 1.50 & 0.197 \\
\hline Level change after last DSC & 3.470 & 1.01 & $<0.001$ & -2.950 & 1.38 & 0.036 \\
\hline Baseline trend & -0.180 & 0.05 & $<0.001$ & 0.180 & 0.07 & 0.009 \\
\hline Trend change after initial DSC & -0.050 & 0.08 & 0.519 & -0.030 & 0.11 & 0.773 \\
\hline Trend change after last DSC & 0.140 & 0.07 & 0.049 & -0.090 & 0.10 & 0.361 \\
\hline \multicolumn{7}{|c|}{ Without cardiovascular comorbidity } \\
\hline Baseline level & 58.600 & 0.91 & $<0.001$ & 49.380 & 1.18 & $<0.001$ \\
\hline Level change after initial DSC & -2.950 & 1.30 & 0.026 & 2.710 & 1.63 & 0.101 \\
\hline Level change after last DSC & 3.150 & 1.19 & 0.01 & -3.290 & 1.50 & 0.031 \\
\hline Baseline trend & -0.110 & 0.06 & 0.056 & 0.170 & 0.08 & 0.024 \\
\hline Trend change after initial DSC & -0.110 & 0.10 & 0.247 & 0.020 & 0.12 & 0.872 \\
\hline Trend change after last DSC & 0.180 & 0.08 & 0.033 & -0.150 & 0.11 & 0.167 \\
\hline \multicolumn{7}{|l|}{ With cardiovascular comorbidity } \\
\hline Baseline level & 59.730 & 1.33 & $<0.001$ & 50.010 & 1.54 & $<0.001$ \\
\hline Level change after initial DSC & -2.660 & 1.92 & 0.171 & 2.850 & 2.21 & 0.201 \\
\hline Level change after last DSC & 0.750 & 1.76 & 0.67 & -1.430 & 2.03 & 0.485 \\
\hline Baseline trend & -0.100 & 0.09 & 0.254 & 0.140 & 0.10 & 0.147 \\
\hline Trend change after initial DSC & 0.003 & 0.14 & 0.983 & -0.090 & 0.16 & 0.565 \\
\hline Trend change after last DSC & 0.010 & 0.12 & 0.956 & 0.040 & 0.14 & 0.761 \\
\hline \multicolumn{7}{|c|}{ Sensitivity analysis: 3-month latency period } \\
\hline Baseline level & 58.830 & 0.85 & $<0.001$ & 45.430 & 1.07 & $<0.001$ \\
\hline Level change after initial DSC & -2.810 & 1.46 & 0.059 & 1.270 & 1.12 & 0.262 \\
\hline Level change after last DSC & 3.220 & 1.25 & 0.012 & -1.930 & 1.12 & 0.092 \\
\hline Baseline trend & -0.100 & 0.05 & 0.064 & 0.390 & 0.06 & $<0.001$ \\
\hline Trend change after initial DSC & -0.090 & 0.10 & 0.358 & -0.240 & 0.09 & 0.010 \\
\hline Trend change after last DSC & 0.110 & 0.09 & 0.241 & -0.180 & 0.09 & 0.055 \\
\hline
\end{tabular}

aUnit is percentage of incident users of tiotropium and LABA.

$D S C=$ drug safety communication; $L A B A=$ long-acting beta-agonist; $S E=$ standard error . 